\title{
CORRELAÇÃO ENTRE A CONTAGEM DE CÉLULAS SOMÁTICAS E COMPOSIÇÃO QUÍMICA NO LEITE CRU RESFRIADO EM PROPRIEDADES DO RIO GRANDE DO NORTE
}

\section{Correlation between somatic cell count and chemical composition of cooled raw milk in properties of Rio Grande do Norte, Brazil}

Vanessa Nunes Silva ${ }^{1}$, Adriano Henrique do Nascimento Rangel ${ }^{1}$, Luciano Patto Novaes ${ }^{l}$, Luis Henrique Fernandes Borba ${ }^{l}$, Rayssa Freire Bezerril ${ }^{1}$, Dorgival Morais de Lima Júnior ${ }^{2 *}$

\section{RESUMO}

Devido aos prejuízos causados pela mastite subclínica na perda de produção e qualidade do leite, o presente estudo teve como objetivo verificar a correlação existente entre a contagem de células somáticas (CCS) e a composição química do leite cru resfriado coletado na região agreste do estado do Rio Grande do Norte nos períodos de seca e chuva. As amostras foram coletadas em sete propriedades leiteiras no período da manhã, entre janeiro de 2010 e março de 2012, e encaminhadas ao Laboratório da Rede Brasileira de Qualidade do Leite (ESALQ/USP). Foram determinados os teores de proteína, gordura, lactose, caseína, sólidos totais, extrato seco desengordurado e nitrogênio ureico, além da CCS e bacteriana total. Os dados foram submetidos à análise de variância, análise de correlação e teste de comparação de médias (Tukey a 5\%). A CCS média foi de 604 mil células/mL, com variação significativa para o período seco (558 mil células $/ \mathrm{mL}$ ) e chuvoso (650 mil células $/ \mathrm{mL}$ ). A CCS correlacionou-se positivamente com os teores de gordura e sólidos totais e negativamente com os teores de lactose do leite bovino armazenado em tanque de resfriamento, independente do período, no agreste do Rio Grande do Norte.

Palavras-chave: lactose; proteína do leite; qualidade do leite; sistema de produção; mastite.

1 Universidade Federal do Rio Grande do Norte (UFRN), Programa de Pós-graduação em Produção Animal, Macaíba, RN, Brasil.

2 Universidade Federal de Alagoas (UFAL), Campus Arapiraca, Av. Manoel Severino Barbosa, s/n, Bom Sucesso, 57309-005, Arapiraca, AL, Brasil. E-mail: juniorzootec@yahoo.com.br

* Autor para correspondência. 


\begin{abstract}
Due to the damage caused by subclinical mastitis in loss of production and quality of milk, the present study aimed to verify the correlation between somatic cell count (SCC) and the chemical composition of cooled raw milk collected in the Agreste region of Rio Grande do Norte, Brazil, in drought and rain seasons. Samples were collected in seven dairy farms during morning time, between January 2010 and March 2012, and sent to the Brazilian et of Milk Quality Laboratory (ESALQ/ USP). The contents of protein, fat, lactose, casein, total solids, nonfat dry extract and urea nitrogen, besides of SCC and total bacterial count were performed. Data were submitted to analysis of variance, correlation analysis and comparison of means by Tuckey test , 5\%. The average SCC was 604,000 cells $/ \mathrm{mL}$ and had significant variation in the dry period $(558000$ cells $/ \mathrm{mL})$ and rainy $(650000$ cells $/ \mathrm{mL})$. The SCC was positively correlated with fat and total solids but negatively with the lactose cow's milk of bulk tank, regardless of the season in the Agreste of Rio Grande do Norte.
\end{abstract} Keywords: lactose; milk protein; milk quality; production system, mastitis.

\section{INTRODUÇÃO}

De acordo com Harmon (1994), vários fatores podem influenciar a variação da contagem de células somáticas (CCS) no leite de vacas em lactação, como idade, ordem de parto, período de lactação, mês e estação do ano, entre outros, porém o estado de infecção do úbere é o principal fator responsável pela variação da CCS. Como o número de células somáticas aumenta em resposta à inflamação do úbere, a CCS torna-se um método bastante eficaz para se estimar a presença de mastite subclínica no rebanho (BRITO, M. A. V. P., 1999). A mastite subclínica está entre as principais doenças em gado leiteiro, causando grandes prejuízos aos produtores, principalmente devido à redução na produção de leite, por ocorrência de alterações nas células epiteliais secretoras e na permeabilidade vascular no alvéolo secretor durante a infecção (RUEGG, 2003; ZAFALON et al., 2007).

Segundo Brito, J. R. F. (1999) no leite de vacas sadias são encontradas baixas quantidades de células somáticas, geralmente menos de 50.000 por mililitro (células $/ \mathrm{mL}$ ). Entretanto, diversos autores consideram que CCS com até 250.000 células/mL não afeta a produção e a qualidade do leite produzido. O Ministério da Agricultura, Pecuária e Abastecimento (MAPA) publicou em 2011 a Instrução Normativa (IN) atualmente vi gente no país, a IN no 62 (BRASIL, 2011). No regulamento consta a redefinição do cronograma e alterações nos prazos anteriormente propostos pela IN n ${ }^{\circ} 51$ (Regulamento Técnico de Produção, Identidade e Qualidade do Leite Tipo A, do Leite Tipo B, do Leite Tipo C e do Leite Cru Refrigerado), para o atendimento dos requisitos de qualidade, incluindo a contagem de células somáticas no leite. Segundo essa normativa, a partir de janeiro de 2013, nas regiões Norte e Nordeste, a CCS que podia alcançar 750 mil células/mL, passou para o limite máximo 600 mil células/ mL. Além disso, há um escalonamento nos prazos e limites para a redução de CCS até o ano de 2016, até atingir 400 mil células/mL.

A CCS é considerada como um dos principais critérios de qualidade do leite, pois está correlacionada com a composição, o rendimento industrial e a segurança alimentar. Para os produtores, a CCS do leite indica a sanidade das glândulas mamárias das vacas, e sinaliza perdas significativas de produção e alterações da qualidade do leite (PHILPOT, NICKERSON, 2002; BUENO et al., 2005; 
BRAGA et al., 2006; RANGEL et al. 2013). Para a indústria, significa problemas no processamento do leite e redução no rendimento, em razão dos teores inferiores de caseína, gordura e lactose, que resulta em produtos de baixa qualidade e estabilidade (BRITO, J. R. F.,1999). De acordo com a literatura, o aumento da CCS altera a composição do leite, a atividade enzimática,o tempo de coagulação e a produtividade e qualidade dos derivados lácteos (KITCHEN, 1981; SCHÄELLIBAUM, 2000; CASSIANO et al., 2007, SARAN NETTO et al., 2009).

Este trabalho teve como objetivo verificar a correlação existente entre a CCS, principal indicador da mastite subclínica e a composição química do leite coletado em tanques na região agreste do estado do Rio Grande do Norte nos períodos de seca e chuva.

\section{MATERIAL E MÉTODOS}

Durante 27 meses (janeiro de 2010 a março de 2012) foram coletadas 532 amostras de leite do tanque de resfriamento em diferentes propriedades localizadas na região agreste no Estado do Rio Grande do Norte. O clima característico da região é tropical chuvoso com época seca e chuvosa. A época chuvosa vai de fevereiro a julho e a seca de agosto a janeiro, com precipitação pluviométrica média de $855 \mathrm{~mm}$ ao ano. A temperatura média é $25,3{ }^{\circ} \mathrm{C}$ e a umidade relativa média de $79,0 \%$ (IDEMA, 2013).

A Tabela 1 apresenta a localização, o sistema de alimentação e a composição racial do rebanho das sete propriedades avaliadas. Todas as propriedades possuíam sistema de ordenha mecanizada.

Foram realizadas coletas mensais em duplicata, totalizando 38 coletas e 76 amostras por propriedade. As coletas foram realizadas nos tanques de resfriamento no período da manhã. O procedimento de coleta foi realizado após a homogeneização por meio de agitação mecânica, e posteriormente a retirada do tanque foi com o auxílio de uma concha de aço inoxidável higienizada. As amostras de leite foram identificadas e acondicionadas em frascos plásticos de $40 \mathrm{~mL}$, contendo o conservante químico Bronopol ${ }^{\circledR}$ (2-bromo-2-nitro1,3-propanodiol), mantidas em temperatura entre $2{ }^{\circ} \mathrm{C}$ e $6{ }^{\circ} \mathrm{C}$ e enviadas ao laboratório da Clínica do Leite da Escola Superior de

Tabela 1 - Caracterização das fazendas avaliadas na região do Agreste do Rio Grande do Norte

\begin{tabular}{|c|c|c|c|c|c|}
\hline Fazenda & Município & $\begin{array}{l}\text { Sistema de } \\
\text { alimentação }\end{array}$ & $\begin{array}{l}\text { Composição } \\
\text { racial }\end{array}$ & $\begin{array}{c}\text { Número de } \\
\text { vacas ordenhadas }\end{array}$ & $\begin{array}{l}\text { Produção total } \\
\text { de leite (L/dia) }\end{array}$ \\
\hline 1 & São Pedro & Semi-confinado & $\begin{array}{l}\text { Girolando } 3 / 4 \\
\text { e 7/8 Holandês }\end{array}$ & 125 & 1.600 \\
\hline 2 & Brejinho & Semi-confinado & Girolando 3/4 & 105 & 1.200 \\
\hline 3 & Ielmo Marinho & $\begin{array}{c}\text { Confinado - } \\
\text { LooseHousing }\end{array}$ & $\begin{array}{c}\text { 7/8 Hol e } \\
\text { Holandês PC }\end{array}$ & 281 & 5.026 \\
\hline 4 & $\begin{array}{l}\text { São José } \\
\text { de Mipibu }\end{array}$ & Semi-confinado & $\begin{array}{l}\text { Girolando } 3 / 4 \\
\text { e } 7 / 8 \text { Holandês }\end{array}$ & 166 & 1.950 \\
\hline 5 & Extremoz & Semi-confinado & $\begin{array}{l}\text { Girolando3/4 } \\
\text { e 7/8 Holandês }\end{array}$ & 75 & 900 \\
\hline 6 & Monte Alegre & Confinado & Jersey P.O & 48 & 720 \\
\hline 7 & Goianinha & Semi-confinado & Girolando 3/4 & 177 & 2.100 \\
\hline
\end{tabular}


Agricultura "Luiz de Queiroz" (ESALQ/ USP), para análise dos componentes do leite.

Para a determinação dos teores de proteína, gordura, lactose e sólidos totais, as amostras foram submetidas à análise por absorção infravermelha (Bentley 2000 ${ }^{\circledR}$; BentleyInstruments Inc., Chasca MN, EUA). As concentrações de nitrogênio ureico no leite (NUL) foram determinadas pelo método enzimático espectrofotométrico (ChemSpeck $150^{\circledR}$; Bentley Instruments Inc., Chasca MN, EUA). A contagem de células somáticas foi determinada utilizando a contagem eletrônica por espectroscopia de infravermelho com transformada de Fourier (IVTF), com o equipamento MILKO SCAN TM (FOSS, Denmark).

Os dados foram submetidos à análise de variância (ANOVA) e teste de comparação de médias. Os efeitos dos diferentes tratamentos sobre cada variável foram comparados por meio do teste de Tukey, ao nível de 5\% de probabilidade. Os procedimentos estatísticos foram conduzidos utilizando-se o PROC GLM e PROC CORR do SAS (STATISTICAL ANALYSIS SYSTEM, versão 9.2., 1997).

\section{RESULTADOS E DISCUSSÃO}

A contagem de células somáticas (CCS), tanto no período seco como chuvoso, apresentou média de 604 mil células $/ \mathrm{mL}$ (Tabela 2), portanto abaixo do limite de 750 mil células/mL estabelecido pela Instrução Normativa 62 (BRASIL, 2011). Todas as propriedades pesquisadas, por fornecem leite para laticínios da região, são alertadas sobre princípios de higiene na ordenha e seu impacto na qualidade do leite.

Com relação à estação do ano, houve nas propriedades diferenças significativas $(\mathrm{p}<0,05)$ para o nível de CCS no leite, com médias de CCS no período chuvoso superiores às observadas no período seco (Tabela 2). Resultados semelhantes foram encontrados por Magalhães et al. (2006) que concluíram que a CCS foi mais elevada no período de maior umidade. Corroborando com estudo anterior, Harmon; Reneau (1993) afirmam que com o aumento da umidade, maior a susceptibilidade do animal a infecções pelo número de patógenos aos quais estaria exposto o animal, favorecendo a incidência de mastite.

No geral, houve correlação positiva entre o teor de gordura no leite (\%) e a CCS (Tabela 3). Isso indica que o leite com elevada CCS é também mais rico em gordura. Esses resultados são consubstanciados pelos estudos realizados por Lima et al. (2006) e Andrade et al. (2009) que verificaram que houve tendência

Tabela 2 - Média e desvio padrão da CCS no leite de propriedades da região Agreste do Rio Grande do Norte nos períodos de chuva e seca

\begin{tabular}{lcc}
\hline & \multicolumn{2}{c}{ Contagem de células somáticas $\left(\times 10^{3} / \mathrm{mL}\right)$} \\
\hline & Seca & Chuva \\
\cline { 2 - 3 } Propriedade 1 & $1116 \pm 65^{\mathrm{b}}$ & $1309 \pm 51^{\mathrm{a}}$ \\
Propriedade 2 & $593 \pm 44^{\mathrm{b}}$ & $736 \pm 549^{\mathrm{a}}$ \\
Propriedade 3 & $501 \pm 223^{\mathrm{b}}$ & $621 \pm 54^{\mathrm{a}}$ \\
Propriedade 4 & $178 \pm 9,5^{\mathrm{a}}$ & $146 \pm 9,3^{\mathrm{b}}$ \\
Propriedade 5 & $405 \pm 245^{\mathrm{b}}$ & $545 \pm 243^{\mathrm{a}}$ \\
Propriedade 6 & $518 \pm 141^{\mathrm{a}}$ & $547 \pm 158^{\mathrm{a}}$ \\
Propriedade 7 & $593 \pm 32^{\mathrm{b}}$ & $645 \pm 74^{\mathrm{a}}$ \\
\hline
\end{tabular}

*Médias na mesma linha seguidas de letras iguais não diferem entre si, pelo teste de Tuckey $(\mathrm{p}<0,05)$. 
de aumento no teor de gordura à medida que a CCS aumenta no leite. Pode-se inferir que a elevação da CCS está correlacionada com a infecção microbiana do parênquima secretor do úbere. Lesões no parênquima secretor da glândula mamária podem reduzir a produção de leite e, portanto, pode ocorrer concentração dos sólidos, principalmente a gordura.

Tabela 3 - Correlação entre a contagem de células somáticas e a composição química do leite em propriedades da região Agreste do Rio Grande do Norte, durante os períodos de seca e chuva

\begin{tabular}{|c|c|c|c|c|c|c|c|c|}
\hline & Gordura & Proteína & Lactose & $\mathrm{ST}$ & ESD & NUL & Caseína & $\mathrm{CBT}$ \\
\hline \multicolumn{9}{|c|}{ Propriedade 1} \\
\hline Seca & $0,09^{\text {ns }}$ & $-0,40^{*}$ & $-0,30^{\mathrm{ns}}$ & $-0,05^{\mathrm{ns}}$ & $-0,30^{\mathrm{ns}}$ & $0,20^{\mathrm{ns}}$ & $-0,98^{* *}$ & $0,44^{*}$ \\
\hline Chuva & $0,79^{* *}$ & $0,10^{\mathrm{ns}}$ & $-0,57^{* *}$ & $0,59^{* *}$ & $-0,29^{\mathrm{ns}}$ & $0,14^{\mathrm{ns}}$ & $0,47^{\mathrm{ns}}$ & $-0,65^{* *}$ \\
\hline Geral & $0,54^{* *}$ & $0,12^{\mathrm{ns}}$ & $-0,41^{* *}$ & $0,32^{* *}$ & $-0,11^{\mathrm{ns}}$ & $0,12^{\mathrm{ns}}$ & $0,68^{* *}$ & $-0,13^{\mathrm{ns}}$ \\
\hline \multicolumn{9}{|c|}{ Propriedade 2} \\
\hline Seca & $-0,08^{\mathrm{ns}}$ & $0,53^{* *}$ & $-0,19^{\text {ns }}$ & $-0,02^{\text {ns }}$ & $0,16^{\mathrm{ns}}$ & $0,08^{\text {ns }}$ & $0,88^{* *}$ & $0,83^{* *}$ \\
\hline Chuva & $0,69^{* *}$ & $-0,20^{\mathrm{ns}}$ & $-0,60^{* *}$ & $0,33^{*}$ & $-0,67^{* *}$ & $-0,31^{*}$ & $0,55^{*}$ & $0,29^{\mathrm{ns}}$ \\
\hline Geral & $0,36^{* *}$ & $-0,04^{\mathrm{ns}}$ & $-0,55^{* *}$ & $0,08^{\mathrm{ns}}$ & $-0,48^{* *}$ & $0,04^{\mathrm{ns}}$ & $-0,32^{\mathrm{ns}}$ & $0,49^{* *}$ \\
\hline \multicolumn{9}{|c|}{ Propriedade 3} \\
\hline Seca & $0,51^{* *}$ & $-0,49^{* *}$ & $-0,09^{\mathrm{ns}}$ & $0,35^{\text {ns }}$ & $-0,38^{*}$ & $0,31^{\mathrm{ns}}$ & $-0,94^{* *}$ & $-0,47^{*}$ \\
\hline Chuva & $0,62^{* *}$ & $-0,34^{*}$ & $-0,08^{\mathrm{ns}}$ & $0,51^{* *}$ & $-0,49^{* *}$ & $-0,37^{*}$ & $-0,19^{\mathrm{ns}}$ & $0,60^{* *}$ \\
\hline Geral & $0,59^{* *}$ & $-0,28^{*}$ & $-0,18^{\mathrm{ns}}$ & $0,46^{* *}$ & $-0,45^{* *}$ & $0,12^{\text {ns }}$ & $0,23^{\mathrm{ns}}$ & $-0,36^{* *}$ \\
\hline \multicolumn{9}{|c|}{ Propriedade 4} \\
\hline Seca & $0,72^{* *}$ & $0,06^{\mathrm{ns}}$ & $-0,18^{\mathrm{ns}}$ & $0,61^{* *}$ & $0,03^{\mathrm{ns}}$ & $0,79^{* *}$ & $-0,97^{* *}$ & $0,34^{\mathrm{ns}}$ \\
\hline Chuva & $-0,11^{\text {ns }}$ & $0,29^{*}$ & $0,47^{* *}$ & $0,10^{\mathrm{ns}}$ & $0,40^{* *}$ & $-0,15^{\mathrm{ns}}$ & $0,33^{\mathrm{ns}}$ & $-0,15^{\mathrm{ns}}$ \\
\hline Geral & $0,15^{\mathrm{ns}}$ & $0,31^{* *}$ & $0,00^{\mathrm{ns}}$ & $0,36^{*}$ & $0,27^{*}$ & $0,33^{* *}$ & $0,09^{\text {ns }}$ & $-0,06^{\mathrm{ns}}$ \\
\hline \multicolumn{9}{|c|}{ Propriedade 5} \\
\hline Seca & $0,50^{* *}$ & $0,46^{* *}$ & $-0,59^{* *}$ & $0,61^{* *}$ & $0,44^{* *}$ & $0,54^{* *}$ & $-0,81^{*}$ & $0,15^{\text {ns }}$ \\
\hline Chuva & $0,09^{\text {ns }}$ & $0,34^{*}$ & $-0,17^{\mathrm{ns}}$ & $0,17^{\mathrm{ns}}$ & $0,25^{\text {ns }}$ & $0,27^{\mathrm{ns}}$ & $-0,65^{* *}$ & $0,20^{\mathrm{ns}}$ \\
\hline Geral & $0,26^{*}$ & $0,27^{*}$ & $-0,29^{* *}$ & $0,33^{* *}$ & $0,26^{*}$ & $0,29^{* *}$ & $-0,61^{* *}$ & $0,30^{*}$ \\
\hline \multicolumn{9}{|c|}{ Propriedade 6} \\
\hline Seca & $0,30^{*}$ & $0,48^{* *}$ & $0,46^{* *}$ & $0,44^{* *}$ & $0,48^{* *}$ & $-0,57^{* *}$ & $0,33^{\text {ns }}$ & $-0,59^{* *}$ \\
\hline Chuva & $0,58^{* *}$ & $-0,60^{* *}$ & $-0,87^{* *}$ & $-0,19^{\mathrm{ns}}$ & $-0,85^{* *}$ & $0,27^{\mathrm{ns}}$ & $-0,30^{\mathrm{ns}}$ & $-0,81^{* *}$ \\
\hline Geral & $0,33^{* *}$ & $0,37^{* *}$ & $0,11^{\mathrm{ns}}$ & $0,36^{* *}$ & $0,21^{*}$ & $-0,50^{* *}$ & $0,20^{\mathrm{ns}}$ & $-0,21^{\mathrm{ns}}$ \\
\hline \multicolumn{9}{|c|}{ Propriedade 7} \\
\hline Seca & $0,41^{*}$ & $0,07^{\mathrm{ns}}$ & $-0,52^{* *}$ & $0,26^{\text {ns }}$ & $-0,12^{\mathrm{ns}}$ & $-0,18^{\mathrm{ns}}$ & $0,99^{* *}$ & $-0,18^{\mathrm{ns}}$ \\
\hline Chuva & $0,36^{*}$ & $0,49^{* *}$ & $0,68^{* *}$ & $0,50^{* *}$ & $0,65^{* *}$ & $-0,08^{\mathrm{ns}}$ & $0,38^{\mathrm{ns}}$ & $0,37^{*}$ \\
\hline Geral & $0,39^{* *}$ & $0,39^{* *}$ & $0,32^{* *}$ & $0,47^{* *}$ & $0,41^{* *}$ & $-0,13^{\mathrm{ns}}$ & $0,60^{* *}$ & $0,16^{\mathrm{ns}}$ \\
\hline
\end{tabular}

Nota: $*(\mathrm{p}<0,05) ; * *(\mathrm{p}<0,01) ; \mathrm{NS}=$ não significativo; $\mathrm{ST}=$ sólidos totais; $\mathrm{ESD}=$ Extrato Seco Desengordurado $\mathrm{NUL}=$ nitrogênio ureico do leite; $\mathrm{CBT}=$ Contagem de Bactérias Totais. 
Houve correlação negativa entre a CCS e a lactose (\%) do leite. A lactose é o principal substrato das bactérias mesófilas que colonizam o leite no tanque de resfriamento. Portanto, o aumento da CCS pode estar associado à diminuição da lactose do leite no tanque de resfriamento (MACHADO et al., 2000; VENTURA et al., 2006; RANGEL et al., 2009). Uma inferência interessante é que a metabolização da lactose pelas bactérias resulta em ácidos orgânicos que tornam o leite menos estável ao processamento térmico.

Os níveis de sólidos totais, cuja gordura é o principal componente, correlacionaram-se positivamente com a CCS. Pode-se, mais uma vez, atribuir ao efeito de diluição a elevação dos sólidos totais nos leite com maiores contagens de células somáticas. No caso do ESD não foi possível estabelecer um comportamento padronizado, provavelmente devido aos componentes proteína e lactose serem variáveis de comportamento discrepante, principalmente, em diferentes estações.

A fração nitrogenada não proteica do leite, correspondente ao nitrogênio ureico no leite (NUL), não apresentou padrão na correlação que permita alguma inferência. $\mathrm{O}$ NUL tem uma grande variação, pois deriva da ureia presente na corrente sanguínea e, portanto é responsivo a uma série de componentes dos sistemas de produção animal (DOSKA et al., 2012; SOARES et al., 2013). Provavelmente, o efeito da estação do ano foi sobrepujado por outros componentes do rebanho. Segundo Kgole et al. (2012) o dia do teste no rebanho é o componente responsável por até $50 \%$ da variação no NUL.

A caseína apresentou correlações fortes, tanto negativas como positivas, com a CCS do leite no tanque de resfriamento, principalmente no período seco. Pode-se inferir que a quantidade de caseína presente no leite pode ser afetada por dois mecanismos principais: 1) a elevação da CCS correlaciona-se positivamente com aumento da concentração de caseína, devido à redução da produção de leite; 2) a elevação da CCS correlaciona-se negativamente com a caseína devido à destruição do parênquima secretor e menor secreção de caseína pelas células da glândula mamária (LITWINCZUK et al. 2011). Outra explicação possível, conforme Fernandes et al. (2008) é que a elevada CCS no leite no tanque pode aumentar a proteólise, com consequente degradação da caseína.

\section{CONCLUSÕES}

A CCS correlaciona-se positivamente com os teores de gordura e sólidos totais e negativamente com os teores de lactose do leite bovino armazenado em tanque de resfriamento, independente do período, no agreste do Rio Grande do Norte.

\section{REFERÊNCIAS}

ANDRADE, U. V. C., W. HARTMANN, M. L. MASSON. Isolamento microbiológico, contagem de células somáticas e contagem bacteriana total em amostras de leite. ARS Veterinária, v. 25, n. 3, p. 129-135, 2009.

BRAGA, G. C. et al. Contagem de células somáticas em leite formal de produtores de Marechal cândido Rondon - PR. Archives of Veterinary Science, v. 11, n. 3, p. 80-85, 2006.

BRASIL. Ministério da Agricultura, Pecuária e Abastecimento. Departamento de Inspeção de Produtos de Origem Animal. Instrução Normativa $\mathrm{n}^{\circ} 51$, de 18 de setembro de 2002. Aprova os Regulamentos Técnicos de Produção, Identidade e Qualidade do Leite tipo A, do Leite tipo B, do Leite tipo C, do Leite Pasteurizado e do Leite Cru Refrigerado e o Regulamento Técnico da Coleta de Leite Cru Refrigerado e seu Transporte a Granel, em conformidade com os Anexos a esta Instrução Normativa. Diário Oficial da 
República Federativa do Brasil, Brasília, 20 set. 2002. Seção 1, p. 8-13.

BRASIL. Ministério da Agricultura, Pecuária e Abastecimento. Instrução Normativa $\mathrm{n}^{\mathrm{o}}$ 62, de 29 de dezembro de 2011. Aprova o Regulamento Técnico de Produção, Identidade e Qualidade do Leite tipo A, o Regulamento Técnico de Identidade e Qualidade de Leite Cru Refrigerado, o Regulamento Técnico de Identidade e Qualidade de Leite Pasteurizado e o Regulamento Técnico da Coleta de Leite Cru Refrigerado e seu Transporte a Granel, em conformidade com os Anexos desta Instrução Normativa. Diário Oficial da República Federativa do Brasil, Brasília, 30 dez. 2011. Seção 1, p. 6.

BRITO, J. R. F. O que são e como surgem as células somáticas no leite. In: MINAS LEITE: QUALIDADE DO LEITE E PRODUTIVIDADE DOS REBANHOS LEITEIROS, 1 ., 1999, Juiz de Fora. Anais... Juiz de Fora: Embrapa Gado de Leite, 1999. p. 35-39.

BRITO, M. A. V. P. Influência das células somáticas na qualidade do leite. In: MINAS LEITE: QUALIDADE DO LEITE E PRODUTIVIDADE DOS REBANHOS LEITEIROS, 1., 1999, Juiz de Fora. Anais... Juiz de Fora: Embrapa Gado de Leite, 1999. p. 41-46.

BUENO, V. F. F. et al. Contagem celular somática: relação com a composição centesimal do leite e período do ano no Estado de Goiás. Ciência Rural, v. 35, n. 4, p. 848854, 2005.

CASSIANO, L. A. et al. Contagem de células somáticas em amostras de leite cru na região de Catalão, GO. Higiene Alimentar, v. 21, n. 149, p. 73-81, 2007.

DOSKA, M. C. et al. Sources of variation in milk urea nitrogen in Paraná dairy cows. Revista Brasileira de Zootecnia, v. 41, n. 3, p. $692-697,2012$.

FERNANDES, A. M. et al. Casein fractions of ultra-high temperature milk with different somatic cell counts. Pesquisa Agropecuária Brasileira, v. 43, n. 1, p. 149-152, 2008.

HARMON, R. J. Physiology of mastitis and factors affecting somatic cell counts. Journal of Dairy Science, v. 77, n. 7, p. 2103-2103, 1994.

HARMON, R. J.; RENEAU, J. K. Factors affecting somatic cell counts in milk. In: NATIONAL MASTITIS COUNCIL ANNUAL MEETING, 32., 1993, Arlington. Proceedings... Madison: National Mastitis Council, 1993. p. 48-57.

INSTITUTO DE DESENVOLVIMENTO SUSTENTÁVEL E MEIO AMBIENTE (IDEMA). Perfil do seu município (2013). Natal, 2013. Disponível em: <http://www. idema.rn.gov.br/Conteudo.asp?TRAN=PAST $\mathrm{AC} \& \mathrm{TARG}=983 \& \mathrm{ACT}=\& \mathrm{PAGE}=1 \& \mathrm{PARM}$ $=\& \mathrm{LBL}=>$. Acesso em: 15 maio 2014.

KGOLE, M. L.; VISSER, C.; BANGA, C. B. Environmental factors influencing milk urea nitrogen in South African Holstein cattle. South African Journal of Animal Science, v. 42, n. 5 (Sup.1), p. 459-463, 2012.

KITCHEN, B. J. Review of the progress of dairy science: Bovine mastitis: milk compositional changes and related diagnostic tests. Journal of Dairy Research, v. 48, n. 1, p. 167-188, 1981.

LITWINCZUK, Z. et al. Changes of protein content and its fractions in bovine milk from different cow breeds subject to somatic cell count. Journal of Dairy Science, v. 94, n. 2, p. $684-691,2011$. 
LIMA, M. C. G. et al. Contagem de células somáticas e análises físico-químicas e microbiológicas do leite cru tipo $\mathrm{C}$ produzido na região agreste do estado de Pernambuco. Arquivos do Instituto Biológico, v. 73, n. 1, p. 89-95, 2006.

MACHADO, P. F; PEREIRA, A. R; SARRÍES, G. A. Composição do leite de tanques de rebanhos brasileiros distribuídos segundo sua contagem de células somáticas. Revista Brasileira de Zootecnia, v. 29, n. 6, p. 18831886, 2000.

MAGALHÃES, H. R. et al. Influência de fatores de ambiente sobre a contagem de células somáticas e sua relação com perdas na produção de leite de vacas da raça Holandesa. Revista Brasileira de Zootecnia, v. 35, n. 2, p. 415-421, 2006.

PHILPOT, W. N.; NICKERSON, S. C. Origem e significado das células somáticas. In: Vencendo a luta contra a mastite. Naperville: Milkbizz, 2002. p. 28-37.

RANGEL, A. H. N. et al. Correlação entre a contagem de células somáticas (CCS) e o teor de gordura, proteína, lactose e extrato seco desengordurado do leite. Revista Verde de Agroecologia e Desenvolvimento Sustentável, v. 4, n. 3, p. 57 -60, 2009.

RANGEL, A. H. N. et al. Avaliação da qualidade do leite cru com base na contagem de células somáticas em rebanhos bovinos comerciais no estado do Rio Grande do Norte,
Brasil. Archives of Veterinary Science, v. 18 , n. 1, p. 40-45, 2013.

RUEGG, P. L. Investigation of mastitis problems on farms - Review. Veterinary Clinics of North America: Food Animal Practice, v. 19, n. 1, p. 47-63, 2003.

SARAN NETTO, A. et al. Estudo comparativo da qualidade do leite em ordenha manual e mecânica. Revista do Instituto de Ciência da Saúde, v. 27, n. 4, p. 345-349, 2009.

SCHÄELLIBAUM, M. Efeitos de altas contagens de células somáticas sobre a produção e qualidade de queijos. In: SIMPÓSIO INTERNACIONAL SOBRE QUALIDADE DO LEITE, 2., 2000, Curitiba. Anais... Curitiba: CIETEP/FIEP, 2000. p. 21-26.

SOARES, A. D. et al. Nitrogênio uréico e caseína do leite de búfala em diferentes ordens de parto. Agropecuária Científica no Semiárido, v. 9, n. 2, p. 94-101, 2013.

VENTURA, R. V. et al. Contagem de células somáticas e seus efeitos nos constituintes do leite.In: CONGRESSO BRASILEIRO DE QUALIDADE DO LEITE, 2., Goiânia. Anais... Goiânia: CBQL, 2006. p. 187-189.

ZAFALON, L. F. et al. Mastite subclínica causada por Staphylococcus aureus: custobenefício da antibioticoterapia de vacas em lactação. Arquivo Brasileiro de Medicina Veterinária e Zootecnia, v. 59, n. 3, p. 577 585, 2007. 